\title{
Scopolamine Enhances Generalization between Odor Representations in Rat Olfactory Cortex
}

\author{
Donald A. Wilson \\ Department of Zoology, University of Oklahoma, Norman, Oklahoma 73019, USA
}

\begin{abstract}
Acetylcholine (ACh) has a critical, modulatory role in plasticity in many sensory systems. In the rat olfactory system, both behavioral and physiological data indicate that ACh may be required for normal odor memory and synaptic plasticity. Based on these data, neural network models have hypothesized that ACh muscarinic receptors reduce interference between learned cortical representations of odors within the piriform cortex. In this study, odor receptive fields of rat anterior piriform cortex (aPCX) single-units for alkane odors were mapped before and after either a systemic injection of the muscarinic receptor antagonist scopolamine $(0.5$ $\mathrm{mg} / \mathrm{kg}$ ) or aPCX surface application of $500 \mu \mathrm{M}$ scopolamine (or saline/ACSF controls). Cross-habituation between alkanes differing by two to four carbons was then examined following a 50-sec habituating stimulus. The results demonstrate that neither aPCX spontaneous activity nor odor-evoked activity (receptive field) was affected by scopolamine, but that cross-habituation in aPCX neurons was enhanced significantly by either systemic or cortical scopolamine. These results indicate that scopolamine selectively enhances generalization between odor representations in aPCX in a simple memory task. Given that ACh primarily affects intracortical association fibers in the aPCX, the results support a role for the association system in odor memory and discrimination and indicate an important ACh modulatory control over this basic sensory process.
\end{abstract}

Central cholinergic systems have been implicated in attention and memory, and degeneration of these systems may partially underlie aging/dementia-associated declines in cognitive ability (Olton and Wenk 1987; Fibiger 1991; Everitt and Robbins 1997). Cortical acetylcholine release is elevated during arousal and/or attention (Acquas et al. 1996), and lesions or pharmacological blockade of central cholinergic synapses impairs cognitive functions (Cheal 1981; Coyle et al. 1983).

The olfactory system has been an especially useful model system for studying the role of acetylcholine in memory. Disruption of normal cholinergic function has been implicated in disruption of many forms of odor memory, including simple odor habituation (Hunter and Murray 1989; Paolini and McKenzie 1993), associative odor memory (Roman et al. 1993; Ravel et al. 1994; Ferreira et al. 1999; DeRosa and Hasselmo 2000; Winters et al. 2000; see also Wirth et al. 2000), and odor rule or set learning (Saar et al. 2001). The mechanisms of cholinergic modulation of olfactory memory, however, are unknown.

The olfactory system primarily receives cholinergic input from the basal forebrain (Wenk et al. 1977; Shipley and Ennis 1996), although there is also a small population of intrinsic cholinergic neurons within the olfactory bulb and cortex (Phelps et al. 1992). The major source of acetylcholine (ACh) to the olfactory system is the horizontal limb of

E-MAIL dwilson@ou.edu; FAX (405) 325-2699.

Article and publication are at http://www.learnmem.org/cgi/doi/ $10.1101 / \mathrm{lm} .42601$. the diagonal band of Broca (HLDB), which also receives olfactory input. In fact, activity within the HLDB and ACh release are enhanced by olfactory system activation (Inglis and Fibiger 1995; Linster and Hasselmo 2000). In the olfactory bulb, the first central processor in the olfactory pathway, ACh modulates activity of both output neurons (mitral/tufted cells) and interneurons through both muscarinic and nicotinic receptors (Nickell and Shipley 1988; Ravel et al. 1990; Elaagouby et al. 1991; Castillo et al. 1999). In the piriform cortex, ACh modulates synaptic transmission between pyramidal neurons (association fibers; Hasselmo and Bower 1992; Rosin et al. 1999), modulates pyramidal cell excitability (Linster et al. 1999) and regulates adaptation of pyramidal cell firing to step depolarization (Barkai and Hasselmo 1994). In both the olfactory bulb (Elaagouby and Gervais 1992) and piriform cortex (Hasselmo and Barkai 1995; Saar et al. 2001), ACh also enhances some forms of neural plasticity.

Modeling studies of piriform cortex indicate that ACh may function to reduce interference between different, stored patterns of odor-evoked activity, and therefore, reduce confusion between odorant memories (Hasselmo and Bower 1993; Linster and Hasselmo, 2001). Therefore, a reduction in cholinergic activity within the piriform cortex during odor exposure and learning should result in interference between cortical representations of different odors that could be expressed as a memory impairment.

Neurons within the anterior piriform cortex (aPCX) display odor-receptive fields (Wilson 1998a, 2000b) similar to that reported for both olfactory receptor neurons (Sato et al. 1994; Duchamp-Viret et al. 1999; Malnic et al. 1999) and

LEARNING \& MEMORY 8:279-285 @ 2001 by Cold Spring Harbor Laboratory Press ISSN1072-0502/01 \$5.00

\begin{tabular}{|c|c|c|c|c|c|c|c|c|c|c|c|c|}
\hline$E$ & $A$ & $R$ & $N$ & I & $N$ & $G$ & Q & $M$ & $E$ & $M$ & 0 & $R$ \\
\hline & & & & & & & learnmen & & & & & \\
\hline & & & & & & & 279 & & & & & \\
\hline
\end{tabular}


olfactory bulb mitral/tufted cells (Imamura et al. 1992; Yokoi et al. 1995). However, aPCX neurons are capable of a high degree of discrimination between odors within their receptive fields, a capability not expressed by mitral/tufted cells (Wilson 2000b). For example, habituation to one odor within the receptive field of an aPCX neuron does not generalize to responsiveness to other, highly similar odorants (e.g., varying by only two carbons in molecular length), whereas mitral/tufted cells show substantial generalization/ cross-habituation between odors within their receptive fields (Wilson 2000a,b).

This report examines whether the heightened specificity of responses within the aPCX may be related to the hypothesized (Hasselmo and Bower 1993; Linster and Hasselmo 2001) cholinergic reduction in interference between cortical odor representations mentioned above. The results indicate that the muscarinic ACh receptor antagonist scopolamine enhances cross-habituation (generalization) between odors by aPCX neurons in a simple odor memory test.

\section{RESULTS}

As reported previously, aPCX layer II/III single-units displayed odorant receptive fields for a series of alkanes varying in carbon chain length. Single cells responding reliably to two or three of the test stimuli were used in this data set.

Systemic injection of scopolamine $(0.5 \mathrm{mg} / \mathrm{kg})$ had no significant effect on spontaneous activity of layer II/III aPCX neurons (Fig. 1). Spontaneous activity remained around 0.5 $\mathrm{Hz}$ after either saline $(n=15)$ or scopolamine $(n=12)$ injections (ANOVA, $F(1,25)=0.06$, N.S.). Surgical exposure of the cortex and superfusion with aCSF produced a marked increase in aPCX spontaneous activity over the enclosed cortex (Fig. 1). Similar to systemic injection, however, application of $500 \mu \mathrm{M}$ scopolamine $(n=14)$ directly to the cortical surface had no detectable effect on spontaneous activity compared to aCSF $(n=14$; ANOVA, $F(1,26)=0.06$, N.S.).

Odor-evoked activity was also not affected detectably by either systemic or cortical application of scopolamine. As shown in Figure 2, both the general characteristics of the
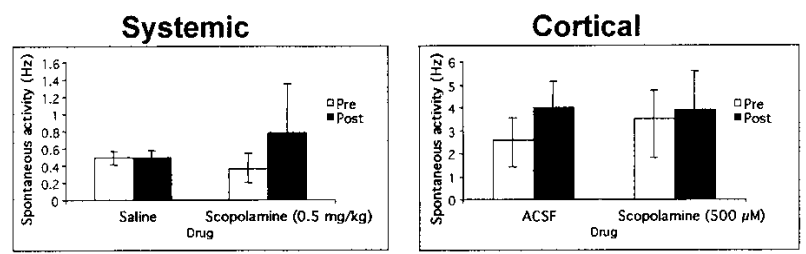

Figure 1 Spontaneous activity pre- and post-systemic (left) or cortical (right) scopolamine. Control animals were injected with saline or had ACSF applied to the cortical surface. Cells in the exposed cortex had substantially higher spontaneous activity than closedskull animals, but scopolamine had no detectable effect on spontaneous activity.

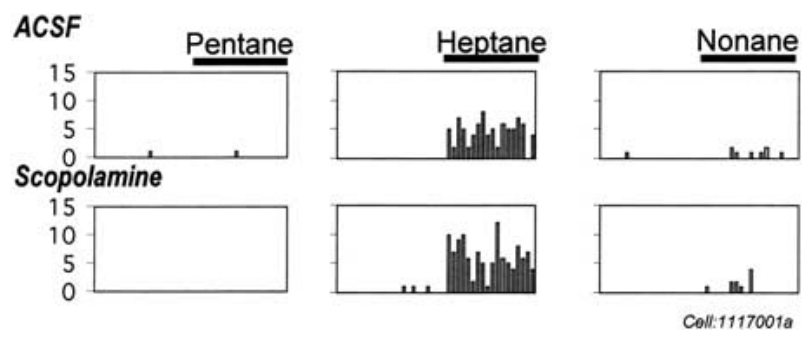

Figure 2 Representative example of single-unit peri-stimulus time histograms (100 ms bin width) of odor responses pre- and postcortical application of scopolamine $(500 \mu \mathrm{M})$. The receptive field of this cell included a vigorous response to heptane, less to nonane, and no response to pentane (2-sec odor stimuli). Re-testing $10 \mathrm{~min}$ after cortical scopolamine application showed no detectable change in the odor receptive field.

receptive field (i.e., which odor was maximally excitatory and which odors were least excitatory) and the quantitative magnitude of odor-evoked responses were unaffected by scopolamine (the cell shown in Fig. 2 was exposed to cortical surface application of scopolamine). For analysis, odor response magnitude (spike count during the two-second odor stimulus-spike count during the two seconds immediately preceding odor onset) after pharmacological manipulation was expressed as a percent of the response magnitude pre-drug. As shown in Figure 3, neither systemic $(n=15 /$ mean; main effect of drug; ANOVA, $F(1,51)=0.21$, N.S.) nor cortical scopolamine ( $n=7-14$ cells/mean; main effect of drug; ANOVA, $F(1,61)=0.01$, N.S.) affected odor response magnitude significantly.

Self-habituation to odor was not affected significantly by either systemic or cortical scopolamine (Fig. 4). Odor responses to a 2 -sec odor pulse were significantly reduced following a 50-sec presentation of the same odor, as reported previously (Wilson 1998a), and the magnitude of this reduction was unaffected by scopolamine.

In cells from control animals, this habituation was highly odor-specific, with minimal cross-habituation of alkanes differing in carbon chain length by two or four carbons. Cells in scopolamine-treated animals, however, showed significant cross-habituation between alkanes (Fig. 4; systemic scopolamine: $n \mathrm{~s}=8-21$ cells/mean; ANOVA,
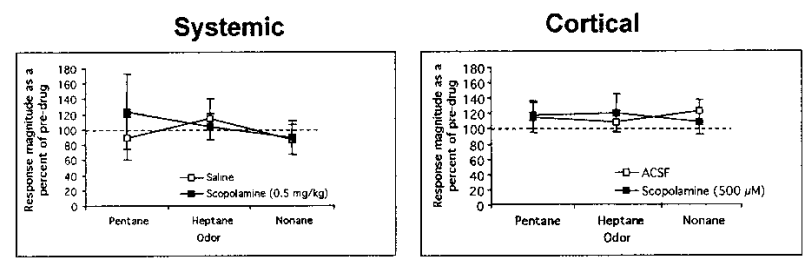

Figure 3 Response magnitude (as expressed as a percent of predrug magnitude) across all three odorants tested pre- and postsystemic (left) or cortical (right) scopolamine. Control animals were injected with saline or had ACSF applied to the cortical surface. Odorant response magnitude was not modified detectably by scopolamine.

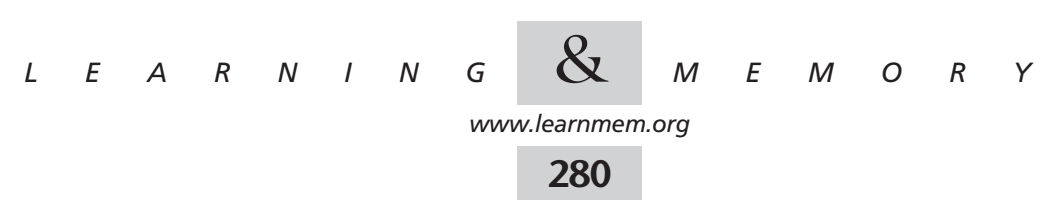



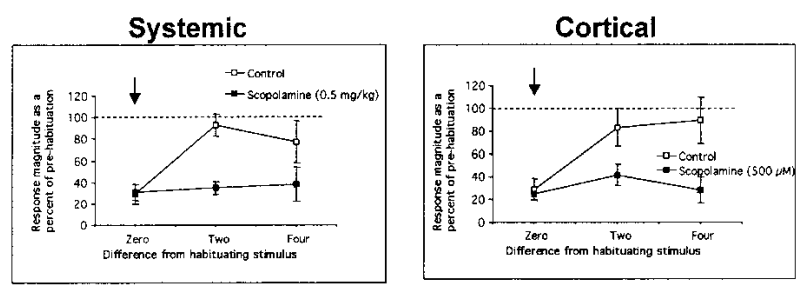

Figure 4 Self- and cross-habituation to odorants pre- and postsystemic (left) or cortical (right) scopolamine. Control animals were injected with saline or had ACSF applied to the cortical surface. Scopolamine had no significant effect on self-habituation but enhanced cross-habituation to other alkane odorants significantly.

main effect of Drug, $\quad F(1,87)=12.28, \quad P<0.01$, and drug $\times$ odor difference interaction, $F(2,87)=4.91, P<0.01$; cortical scopolamine: $n \mathrm{~s}=5-18$ cells/mean; ANOVA, main effect of Drug, $F(1,71)=9.63, P<0.01$, and drug $\times$ odor difference interaction, $F(2,71)=2.35, P=0.10$, N.S.). Post-hoc Fisher tests revealed a significant $(P<0.05)$ effect of scopolamine at the two and four carbon chain length difference in both systemic and cortical application paradigms. The effects of scopolamine were relatively robust, being apparent not only in these averaged data, but also when examined on a cell-by-cell basis. For example, with cortical surface scopolamine treatment, $81 \%$ of individual cells showed at least a $50 \%$ reduction of response magnitude to odors either two or four carbons different than the habituating stimulus. This is compared with only $40 \%$ of ACSF-treated cells. Therefore, as opposed to control cells, habituation to one odor in the presence of scopolamine significantly reduced responses to other, similar odors.

\section{DISCUSSION}

Our results show that the muscarinic receptor antagonist scopolamine selectively enhanced generalization between odors by aPCX single-units in a simple odor memory task (habituation) without producing a detectable effect on spontaneous activity, the magnitude of odor-evoked activity, or habituation itself. This effect was expressed following either systemic injection or direct application of scopolamine to the aPCX surface, indicating direct involvement of cortical muscarinic receptors.

Odor-evoked activity and odor discrimination, as determined by partial mapping of receptive fields was not affected by scopolamine. For example, individual cells that responded to one particular odor and not to another before scopolamine, continued to do so after scopolamine. Odor discrimination as determined by cross-habituation, however, was impaired significantly by scopolamine. In fact, cross-habituation levels under scopolamine were similar to that reported for olfactory bulb mitral/tufted cells (Wilson 2000b). Again, this scopolamine effect appears to be attributable to a blockade of receptors within the aPCX itself, given that aPCX cortical surface application had the same effect as systemic injection. Systemic scopolamine injection has been also shown recently to not affect spontaneous or odor-evoked oscillatory activity of local field potentials recorded in the aPCX, although it significantly modulates field potentials in other regions of the olfactory pathway (Chabaud et al. 2000).

There are at least two interpretations of the scopolamine-induced enhancement in cross-habituation in the aPCX. First, scopolamine may produce a purely sensory deficit wherein similar odors cannot be discriminated by cortical neurons because of a scopolamine-induced change in cortical activation patterns. Therefore, for example, scopolamine could enhance the size of aPCX neuron receptive fields (through disinhibition of association fiber synapses or changes in membrane excitability; Hasselmo and Bower 1992) with a loss of discrimination between odors within that enlarged field. This does not appear to be the case in the present data because scopolamine did not detectably alter aPCX single-unit receptive fields or the magnitude of odor-evoked responses (e.g., Figs. 2 and 3). Similarly, ACh release (via nucleus basalis stimulation) in the auditory cortex does not appear to modify single-unit receptive fields, as long as the release is not specifically, repeatedly paired with an auditory stimulus (Bakin and Weinberger 1996).

The second interpretation of the scopolamine-enhancement of cross-habituation is a confusion in the cortical representation of simple odor memory. Therefore, during post-habituation receptive field mapping, the cell may "recall" incorrectly which odor was experienced during the habituation exposure. This confusion could be mediated by a scopolamine-induced lack of specificity in synaptic plasticity evoked by the prolonged odor exposure. Whereas odor habituation is associated with odor-specific depression of the afferent LOT synapses (Wilson 1998b), the association fiber synapses are also highly plastic and this association fiber plasticity has been hypothesized to be critical for odor memory (Haberly 1985; Hasselmo et al. 1990). According to network modeling of the piriform cortex by Hasselmo and co-workers (Hasselmo et al. 1990; Hasselmo and Barkai 1995), ACh suppression of association fiber synapses during odor learning allows for the selective plasticity necessary for odor memory, while preventing nonselective plasticity that could produce interference between representations of multiple odors within the piriform cortex. Given that the HLDB is activated by olfactory input (Linster and Hasselmo 2000), novel (as used here) or biologically significant odorants could enhance ACh release, which could form a feedback system that allows on-line fine tuning of plasticity and memory formation in the piriform cortex (Linster and Hasselmo 2001). Blockade of piriform ACh receptors, therefore, would produce nonselective synaptic plasticity and confusion or interference between stored representations. These results appear to support this hypoth-

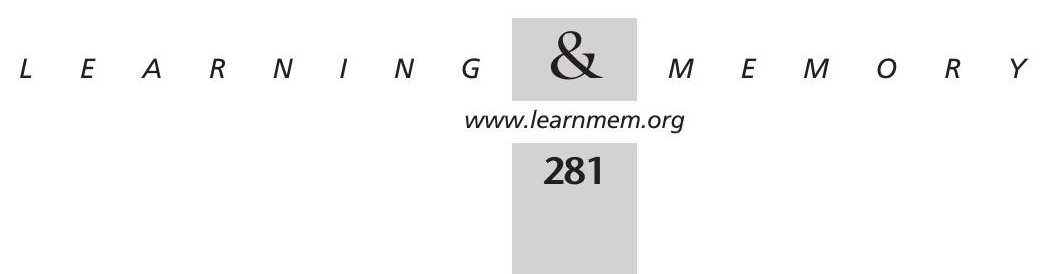


esis, and further, imply a role for cortical association fibers in odor-specific habituation, in addition to that shown previously for afferent synapses (Wilson 1998b).

\section{Comparison With Other Systems}

There are several striking parallels between the olfactory system and the higher-order visual cortices, as described recently by Haberly (2001). In the visual system, peripheral and primary cortical neurons have simple, feature-detecting receptive fields, responding maximally, for example, to a contrast edge or bar of light. In higher order visual cortex, however, such as inferotemporal cortex, receptive fields are much more complex, with maximal responses elicited only by an appropriate combination of features, such as a face (for recent reviews, see Logothetis and Sheinberg 1996; Miyashita and Hayashi 2000; Rolls 2000; Tanaka 2000). In fact, some neurons express view-invariant receptive fields, where the effective stimulus can be rotated around an axis, yet still produce a maximal response in the neuron. Importantly, complex and view-invariant receptive fields of inferotemporal cortex neurons require experience for their formation (Rolls 2000), although the experience can be as little as five seconds (Tovee et al. 1996).

In the olfactory system, as in vision, more peripheral neurons, such as receptor neurons, and mitral/tufted cells appear to function primarily as feature detectors. Both theoretical (Haberly 2001) and recent cross-habituation studies (Wilson 2000a,b), however, suggest that receptive fields in piriform cortex may be similar to higher order, auto-associative cortices, rather than primary sensory cortex. Specifically, piriform cortex receptive fields may be similar to inferotemporal cortex complex visual receptive fields, with individual neurons responding to odors as unique ensembles of features, that once combined, are treated as a single complex stimulus. For example, single units in the aPCX show minimal cross-habituation between binary odor mixtures and their components, suggesting that the aPCX treats the mixture as a completely different stimulus than either of its component features (Wilson 2000a; piriform cortex receptive fields may also be multimodal, responding to the sensory context or reward associations of odors; Schoenbaum and Eichenbaum 1995). If piriform cortex is functioning similar to inferotemporal cortex, then formation of these odor feature ensembles should require some minimal experience (the odors used in this study were all novel to the animal). Without appropriate experience (or with the normal effects of experience blocked by scopolamine as described above) the piriform may not be able to create odor feature ensembles, and therefore may respond to odors based on the presence of specific features alone similar to what has been reported for mitral/tufted cells. Therefore, as shown in this paper, as with feature-detecting mitral/tufted cells (Wilson 2000b), scopolamine-treated aPCX neurons show strong cross-habituation to similar odors. It should also be noted that cholinergic lesions disrupt inferotemporal cortex-mediated visual discriminations (Barefoot et al. 2000).

\section{Comparison With Behavioral Data}

Scopolamine has been reported to impair behavioral odor habituation (Hunter and Murray 1989) and behavioral associative odor memory (DeRosa and Hasselmo 2000; Ravel et al. 1994). This cholinergic modulation of behavioral responses may be mediated by several brain regions in addition to the aPCX (e.g., Ravel et al. 1994; Linster and Hasselmo 1997), however these results should shed light on neural substrates of some of these behavioral effects. It should be noted that the effects of scopolamine reported here for the anesthetized rat may be reduced from those that occur in awake, freely moving animals that could have higher or more dynamic levels of aPCX muscarinic receptor activation.

At least two studies have examined the role of ACh in rat behavioral odor habituation. These studies indicate that systemic scopolamine (Hunter and Murray 1989) and lesions of the horizontal limb of the diagonal band (Paolini and McKenzie 1993) impair the habituation of odor investigation latency and duration. The Hunter and Murray (1989) data are somewhat compromised by general behavioral deficits induced by the scopolamine injections, although the results are interpreted as indicating that odor habituation was reduced by scopolamine. For statistical comparison, however, responses to the habituating odor were compared with responses to a novel odor - responses to the novel odor were expected to differ significantly from the habituation odor (e.g., the animal should investigate a novel odor longer than the habituated odor). A close examination of Figures $3 \mathrm{~B}$ and $4 \mathrm{C}$ in that paper (Hunter and Murray 1989), however, indicates that although $0.5 \mathrm{mg} / \mathrm{kg}$ of scopolamine did eliminate differences between the responses to the habituated odor and the novel odor, the lack of difference appears, in fact, to be attributable to a reduction in responsiveness to the novel odor rather than an increased (less habituated) response to the habituated odor. Therefore, the behavioral scopolamine data of Hunter and Murray (1989) may actually correspond well with the single-unit results observed here in suggesting a scopolamine-induced generalization of odor habituation with relatively little effect on habituation itself.

In addition to odor habituation, ACh also modulates associative learning of behavioral odor responses. For example, scopolamine (at the same systemic dose as used here, $0.5 \mathrm{mg} / \mathrm{kg}$ ) decreased the probability of correct choices in a delayed match to sample odor task, even with no delay imposed between sampling and match choice (Ravel et al. 1992). Similarly, in a simultaneous odor discrimination task requiring memory of odor pairs, scopolamine $(0.5 \mathrm{mg} / \mathrm{kg})$ significantly impaired acquisition of

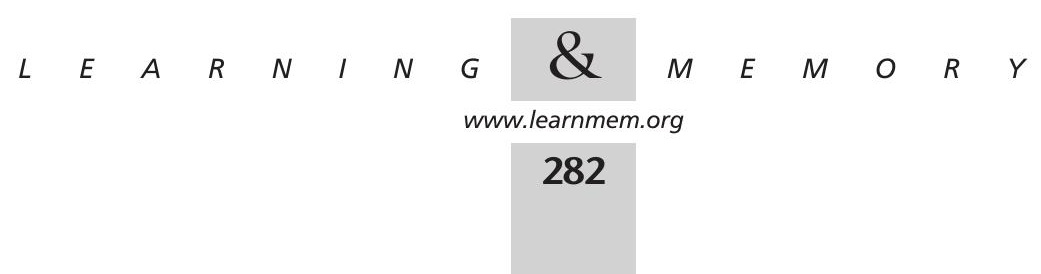




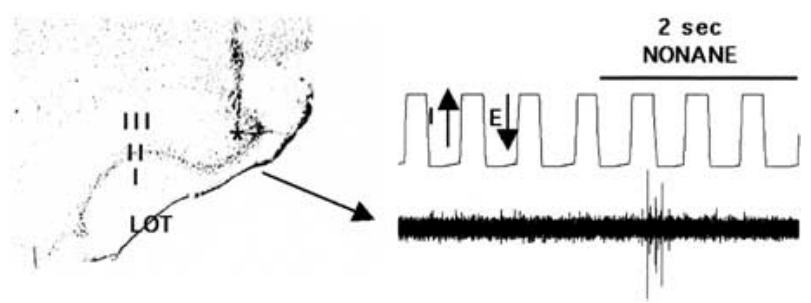

Figure 5 Cresyl violet-stained coronal section through aPCX showing electrode tract and example of an odor response from a layer II/III neuron recorded at the asterisk (single unit extracted for analysis from this raw recording with template-matching). Single units used in this study were from aPCX layer II or III. Respiratory cycle was determined from chest wall movement. (E) Exhalation; (I) inhalation.

overlapping pairs, yet had little effect on nonoverlapping, distinct pairs (DeRosa and Hasselmo 2000). These results have been interpreted as a scopolamine-induced increase in interference between odorant representations in the olfactory system, similar to that reported here at the aPCX singlecell level.

\section{Conclusions}

Whereas both receptor neurons and olfactory bulb mitral cells have odor-receptive fields that imply a high degree of odor discrimination near the periphery, both behavioral (Slotnick and Berman 1980; Staubli et al. 1987) and physiological (Wilson 2000a,b) data indicate that the piriform cortex is critically involved in discrimination and memory of complex and/or very similar odorants. The piriform cortex has been hypothesized to be involved in synthesizing odorant features, extracted by more peripheral olfactory structures, into perceptual odor wholes and perhaps including multi-modal associations, similar to the higher-order cortical processing of complex visual stimuli (Hasselmo et al. 1990; Haberly 2001). This synthesis may involve rapid synaptic plasticity that creates a unique combinatorial representation of the multiple features of a single odorant, or the multiple components of an odorant mixture (Haberly 1985; Lynch 1986; Hasselmo et al. 1990; Wilson, 2001). Piriform cortex synaptic plasticity, therefore, may be a normal part of processing complex odorants, in addition to being required for more traditional memory tasks. Therefore, cholinergic modulation of this cortical plasticity (Hasselmo and Barkai 1995; Saar et al. 2001) and of cortical odor representations (this data) may underlie the behavioral deficits in olfactory behavior observed following manipulations of the cholinergic system.

\section{MATERIALS AND METHODS}

Long-Evans hooded rats, anesthetized with urethane $(1.5 \mathrm{~g} / \mathrm{kg})$ and freely breathing were used as subjects. A monopolar, tungsten electrode was placed in the lateral olfactory tract (LOT) to allow physiological placement of a tungsten microelectrode (5-12 Mohm) into layer II or III of the aPCX, as described previously (Wilson 1998a).
The recording electrode was lowered from the dorsal skull surface in both preparations described below. Recordings were made from neurons in layer II/III, and confirmed as single units with autocorrelation display of refractory periods and in some cases, templatematching (Spike2, CED, Inc). The respiratory cycle was monitored with a piezoelectric device sensitive to chest wall movements.

Odorant stimulation was performed with computer-driven solenoids adding saturated odorant vapor into a clean, humidified airstream $(800 \mathrm{~mL} / \mathrm{min})$ to produce $10^{-1}$ dilutions, as described previously (Wilson 2000a). Odorants consisted of $0.1 \mathrm{~mL}$ of pentane, heptane, or nonane applied to syringe filters. Each odorant had its own solenoid and syringe filters were located downstream of the solenoids, therefore the solenoids were not contaminated by odorants. Odorant stimulation was initiated at the transition from inhalation to exhalation and had a duration of either $2 \mathrm{sec}$ (test stimuli) or $50 \mathrm{sec}$ (habituating stimuli). Individual animals were exposed to a particular habituating stimulus only once. Baseline odorant-receptive field mapping involved at least a 60 -sec interstimulus interval.

The effects of the acetylcholine muscarinic receptor antagonist scopolamine on single-unit spontaneous and odor-evoked activity was examined in two ways. Systemic manipulation involved an i.p. injection of either $0.5 \mathrm{mg} / \mathrm{kg}$ scopolamine-HBr (Sigma) or equal volume saline control. Odorant-receptive fields were mapped before and $30-90 \mathrm{~min}$ after the systemic injection followed by habituation to one of the odors and receptive field remapping. In different animals, the aPCX was exposed by careful removal of the skull overlying the aPCX before electrode implantation. The dura was removed and the cortex bathed in artificial cerebrospinal fluid (aCSF, $124 \mathrm{mM} \mathrm{NaCl}, 5 \mathrm{mM} \mathrm{KCl}, 1.24 \mathrm{mM} \mathrm{KH}_{2} \mathrm{PO}_{4}, 2.4 \mathrm{mM} \mathrm{CaCl}$, $1.3 \mathrm{mM} \mathrm{MgSO}_{4}, 26 \mathrm{mM} \mathrm{NaHCO}_{3}, 10 \mathrm{mM}$ glucose). As noted below, spontaneous activity in the exposed cortex preparation was higher than in the enclosed cortex preparation, which could be caused by trauma of dissection or composition of the aCSF. Odor responses in these animals, however, appeared normal. Odorant-receptive fields were mapped, then the aCSF was removed by absorption and replaced with either $500 \mu \mathrm{M}$ scopolamine in aCSF or aCSF control. Receptive field remapping and habituation were repeated at least 5 min after surface application.

A typical experiment involved mapping the odorant receptive field twice, followed by the pharmacological manipulation. After a delay appropriate for the mode of drug application, the receptive field was then remapped and the animal habituated to one of the three odors. Receptive field remapping then occurred 20-50 sec after the end of the habituation stimulus and again at least $2 \mathrm{~min}$ later. For statistical analyses, the number of cells/group varied between different measures because of differences in odor responsiveness (i.e., whether the cell responded to all three odors tested or not) and which odor was selected to be the habituation odor (i.e., whether it was pentane or nonane that allowed testing of length difference of both two and four carbons, or if it was heptane, which only allowed testing differences of two carbons). In addition, those cells showing no initial spontaneous activity $(0 \mathrm{~Hz})$ were not included in statistical comparisons of change in spontaneous activity rates. In some animals, electrode placements were verified at the end of the experiment in cresyl violet-stained coronal sections (Fig. 5).

\section{ACKNOWLEDGMENTS}

This work was supported by National Institute of Deafness and Communication Disorders grant DC03906 to D.A.W. I thank Regina Sullivan for comments on an earlier version of this manuscript. 
The publication costs of this article were defrayed in part by payment of page charges. This article must therefore be hereby marked "advertisement" in accordance with 18 USC section 1734 solely to indicate this fact.

\section{REFERENCES}

Acquas, E., Wilson, C., and Fibiger, H.C. 1996. Conditioned and unconditioned stimuli increase frontal cortical and hippocampal acetylcholine release: Effects of novelty, habituation and fear. $J$. Neurosci. 16: 3089-3096

Bakin, J.S. and Weinberger, N.M. 1996. Induction of a physiological memory in the cerebral cortex by stimulation of the nucleus basalis. Proc. Natl. Acad. Sci. 93: 11219-11224.

Barefoot, H.C., Baker, H.F., and Ridley, R.M. 2000. Synergistic effects of unilateral immunolesions of the cholinergic projections from the basal forebrain and contralateral ablations of the inferotemporal cortex and hippocampus in monkeys. Neurosci. 98: 243-251.

Barkai, E. and Hasselmo, M.E. 1994. Modulation of the input/output function of rat piriform cortex pyramidal cells. J. Neurophysiol. 72: 644-658.

Castillo, P.E., Carleton, A., Vincent, J.D., and Lledo, P.M. 1999. Multiple and opposing roles of cholinergic transmission in the main olfactory bulb. J. Neurosci. 19: 9180-9191.

Chabaud, P., Ravel, N., Wilson, D.A., Mouly, A.M., Vigouroux, M., Farget, V., and Gervais, R. 2000. Exposure to behaviorally relevant odour reveals differential characteristics in rat central olfactory pathways as studied through oscillatory activities. Chem. Senses 25: 561-573.

Cheal, M.L. 1981. Scopolamine disrupts maintenance of attention rather than memory processes. Behav. Neural. Biol. 33: 163-187.

Coyle, J.T., Price, D.L., and DeLong, M.E. 1983. Alzheimer's disease: A disorder of cortical cholinergic innervation. Science 219: 1184-1188.

DeRosa, E. and Hasselmo, M.E. 2000. Muscarinic cholinergic neuromodulation reduces proactive interference between stored odor memories during associative learning in rats. Behav. Neurosci. 114: 32-41.

Duchamp-Viret, P., Chaput, M.A., and Duchamp, A. 1999. Odor response properties of rat olfactory receptor neurons. Science 284: 2171-2174.

Elaagouby, A. and Gervais, R. 1992. ACh-induced long-lasting enhancement in excitability of the olfactory bulb. NeuroReport 3: 10-12.

Elaagouby, A., Ravel, N., and Gervais, R. 1991. Cholinergic modulation of excitability in the rat olfactory bulb: Effect of local application of cholinergic agents on evoked field potentials. Neurosci. 45: 653-662.

Everitt, B.J. and Robbins, T.W. 1997. Central cholinergic systems and cognition. Ann. Rev. Psychol. 48: 649-684.

Ferreira, G., Gervais, R., Durkin, T.P., and Levy, F. 1999. Postacquisition scopolamine treatments reveal the time course for the formation of lamb odor recognition memory in parturient ewes. Behav. Neurosci. 113: 136-142.

Fibiger, H.C. 1991. Cholinergic mechanisms in learning, memory and dementia: A review of recent evidence. TINS 14: 220-223.

Haberly, L.B. 1985. Neuronal circuitry in olfactory cortex: Anatomy and functional considerations. Chem. Senses 10: 219-238.

- 2001. Parallel-distributed processing in olfactory cortex: New insights from morphological and physiological analysis of neuronal activity. Chem. Senses 26: 551-576.

Hasselmo, M.E. and Bower, J.M. 1992. Cholinergic suppression specific to intrinsic not afferent fiber synapses in rat piriform (olfactory) cortex. $J$. Neurophysiol 67: 1222-1229.

- 1993. Acetylcholine and memory, TINS 16: 218-222.

Hasselmo, M.E. and Barkai, E. 1995. Cholinergic modulation of activity-dependent synaptic plasticity in the piriform cortex and associative memory function in a network biophysical simulation. $J$. Neurosci. 15: 6592-6604.

Hasselmo, M.E., Wilson, M.A., Anderson, B.P., and Bower, J.M. 1990 Associative memory function in piriform (olfactory) cortex: Computational modeling and neuropharmacology. Cold Spring Harbor Symp. Quant. Biol. 55: 599-610.
Hunter, A.J. and Murray, T.K. 1989. Cholinergic mechanisms in a simple test of olfactory learning in the rat. Psychopharmacol. 99: 270-275.

Imamura, K., Mataga, N., and Mori, K. 1992. Coding of odor molecules by mitral/tufted cell in rabbit olfactory bulb. I. Aliphatic compounds. $J$. Neurophysiol. 68: 1986-2002.

Inglis, F.M. and Fibiger, H.D. 1995. Increases in hippocampal and frontal cortical acetylcholine release associated with presentation of sensory stimuli. Neurosci. 66: 81-86.

Linster, C. and Hasselmo, M.E. 1997. Modulation of inhibition in a model of olfactory bulb reduces overlap in the neural representation of olfactory stimuli. Behav. Brain Res. 84: 117-127.

. 2000. Neural activity in the horizontal limb of the diagonal band of Broca can be modulated by electrical stimulation of the olfactory bulb and cortex in rats. Neurosci. Letts. 282: 157-160.

- 2001. Neuromodulation and the functional dynamics of piriform cortex. Chem. Senses 26: 585-594.

Linster, C., Wyble, B.P., and Hasselmo, M.E. 1999. Electrical stimulation of the horizontal limb of the diagonal band of Broca modulates population EPSP's in piriform cortex. J. Neurophysiol. 81: 2737-2742.

Logothetis, N.K. and Sheinberg, D.L. 1996. Visual object recognition. Annu. Rev. Neurosci. 19: 577-621.

Lynch, G. 1986. Synapses, circuits and the beginnings of memory. MIT Press, Cambridge, MA.

Malnic, B., Hirono, J., Sato, T., and Buck, L.B. 1999. Combinatorial receptor codes for odors. Cell 96: 713-723

Miyashita, Y. and Hayashi, T. 2000. Neural representation of visual objects: Encoding and top-down activation. Curr. Opin. Neurobiol. 10: $187-194$.

Nickell, W.T. and Shipley, M.T. 1988. Neurophysiology of magnocellular forebrain inputs to the olfactory bulb in the rat: frequency potentiation of field potentials and inhibition of output neurons. $J$. Neurosci. 8: 4492-4502.

Olton, D.S. and Wenk, G.L. 1987. Dementia: Animal models of the cognitive impairments produced by degeneration of the basal forebrain cholinergic system. In Psychopharmacology: The third generation of progress. (ed. H.Y. Meltzer), pp. 941-953. Raven Press, New York.

Paolini, A.G. and McKenzie, J.S. 1993. Effects of lesions in the horizontal diagonal band nucleus on olfactory habituation in the rat. Neuroscience 57: 717-724.

Phelps, P.E., Houser, C.R., and Vaughn, J.E. 1992. Small cholinergic neurons within fields of cholinergic axons characterize olfactory-related regions of rat telencephalon. Neurosci. 48: 121-136.

Ravel, N., Akaoka, H., Gervais, R., and Chouvet, G. 1990. The effect of acetylcholine on rat olfactory bulb unit activity. Brain Res. Bull 24: 151-155.

Ravel, N., Vigouroux, M., Elaagouby, A., and Gervais, R. 1992. Scopolamine impairs delayed matching in an olfactory task in rats. Psychopharmacol. 109: 439-443.

Ravel, N., Elaagouby, A., and Gervais, R. 1994. Scopolamine injection into the olfactory bulb impairs short-term olfactory memory in rats. Behav Neurosci. 108: 317-324.

Rolls, E.T. 2000. Functions of the primate temporal lobe cortical visual areas in invariant visual object and face recognition. Neuron 27: 205-218.

Roman, F.S., Simonetto, I., and Soumireu-Mourat, B. 1993. Learning and memory of odor-reward association: Selective impairment following horizontal diagonal band lesions. Behav. Neurosci. 107: 72-81.

Rosin, J.F., Datiche, F., and Cattarelli, M. 1999. Modulation of the piriform cortex activity by the basal forebrain: an optical recording study in the rat. Brain Res. 820: 105-111.

Saar, D., Grossman, Y., and Barkai, E. 2001. Long-lasting cholinergic modulation underlies rule learning in rats. J. Neurosci. 21: 1385-1392.

Sato, T., Hirono, J., Tonoike, M., and Takebayashi, M. 1994. Tuning specificities to aliphatic odorants in mouse olfactory receptor neurons and their local distribution. J. Neurophysiol. 72: 2980-2989.

Schoenbaum, G. and Eichenbaum, H. 1995. Information coding in the

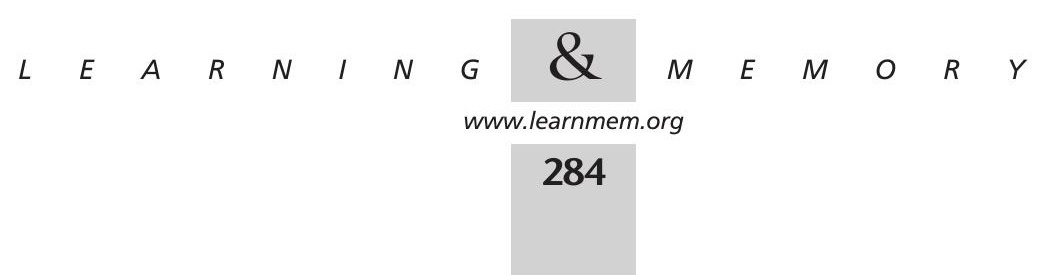


rodent prefrontal cortex. I Single-unit activity in orbitofrontal cortex compared with that in pyriform cortex. J. Neurophysiol. 74: 733-750.

Shipley, M.T. and Ennis, M. 1996. Functional organization of the olfactory system. J. Neurobiol 30: 123-176.

Slotnick, B.M. and Berman, E.J. 1980. Transection of the lateral olfactory tract does not produce anosmia. Brain Res. Bull. 5: 141-152.

Staubli, U., Schottler, F., Nejat-Bina, D. 1987. Role of dorsomedial thalamic nucleus and piriform cortex in processing olfactory information. Behav. Brain Res. 25: 117-125.

Tanaka, K. 2000. Mechanisms of visual object recognition studied in monkeys. Spatial Vision 13: 147-163.

Tovee, M.J., Rolls, E.T., and Ramachandran, V.S. 1996. Rapid visual learning in neurones of the primate temporal visual cortex. NeuroReport. 7: 2757-2760.

Wenk, H., Meyer, U., and Bigl, V. 1977. Centrifugal cholinergic connections in the olfactory system of rats. Neurosci. 2: 797-812.

Wilson, D.A. 1998a. Habituation of odor responses in the rat anterior piriform cortex. J. Neurophysiol. 79: 1425-1440.

. 1998b. Synaptic correlates of odor habituation in the rat anterior piriform cortex. J. Neurophysiol. 80: 998-1001.

\footnotetext{
2000a. Odor specificity of habituation in the rat anterior piriform cortex. J. Neurophysiol. 83: 139-145.

- 2000b. A comparison of odor receptive field plasticity in the rat olfactory bulb and anterior piriform cortex. J. Neurophysiol. 84: 3036-3042.

2001. Receptive fields in the rat piriform cortex. Chem. Senses 26: 577-584.

Winters, B., Matheson, W.R., McGregor, I.S., and Brown, R.E. 2000. An automated two-choice test of olfactory working memory in the rat: Effect of scopolamine. Psychobiol. 28: 21-31.

Wirth, S., Lehmann, O., Bertrand, F., Lazarus, C., Jeltsch, H., and Cassel, J.C. 2000. Preserved olfactory short-term memory after combined cholinergic and serotonergic lesions using 192 IgG-saporin and 5,7-digydroxytryptamine in rats. NeuroReport 11: 347-350.

Yokoi, M., Mori, K., and Nakanishi, S. 1995. Refinement of odor molecule tuning by dendrodendritic synaptic inhibition in the olfactory bulb. Proc. Natl. Acad. Sci. 92: 3371-3375.
}

Received June 19, 2001; accepted in revised form August 15, 2001. 


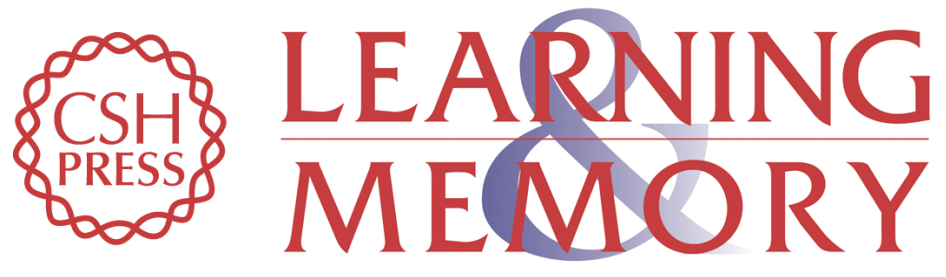

\section{Scopolamine Enhances Generalization between Odor Representations in Rat Olfactory Cortex}

Donald A. Wilson

Learn. Mem. 2001, 8:

Access the most recent version at doi:10.1101//m.42601

References This article cites 21 articles, 2 of which can be accessed free at: http://learnmem.cshlp.org/content/8/5/279.full.html\#ref-list-1

License

Email Alerting Receive free email alerts when new articles cite this article - sign up in the box at the Service top right corner of the article or click here. 